\title{
Anthraquinone Derivative Chiral Schiff Base Copper(II) Complexes for Enzyme Type Bio-Fuel Cell Mediators
}

\author{
Yuto Takeuchi and Takashiro Akitsu \\ Department of Chemistry, Faculty of Science, Tokyo University of Science, Tokyo 162-8601, Japan
}

\begin{abstract}
Electrochemically, laccase, a family of multi-copper oxidase, has specificity for performing not only one-electron oxidation of phenolic-related compounds but also four-electron reduction of oxygen, which is expected to be a cathode of biofuel cells. We have prepared three amino-acid derivatives (for enhancing affinity to laccase) and one control (just for determining redox behavior of ligands and $\mathrm{Cu}(\mathrm{II} / \mathrm{I})$ ) copper(II) complexes 0-3 having phenolic-related ligands involving anthraquinone moiety. Enhancing current density of electron transfer between the cathode (composed of electron conducting materials such as Nafion and carbon nanotube) and laccase could be observed for all 1-3 acting as good mediators according to (spectro)electrochemical results.
\end{abstract}

Key words: Biofuel cells, oxygen reduction, Schiff base, $\mathrm{Cu}(\mathrm{II})$ complex, anthraquinone.

\section{Introduction}

Laccase has been used as a cathode enzyme of biofuel cells [1]. Besides direct electron transfer, a certain mediator such as metal nanoparticles, metal complexes, or redox-active organic compounds, may be necessary to improve the quality of efficiently transfer electrons to the enzyme. Generally, nanoparticle mediator is advantageous spatially (inclusion into the enzyme) and disadvantageous in terms of quantity of electricity basis (namely low current density).

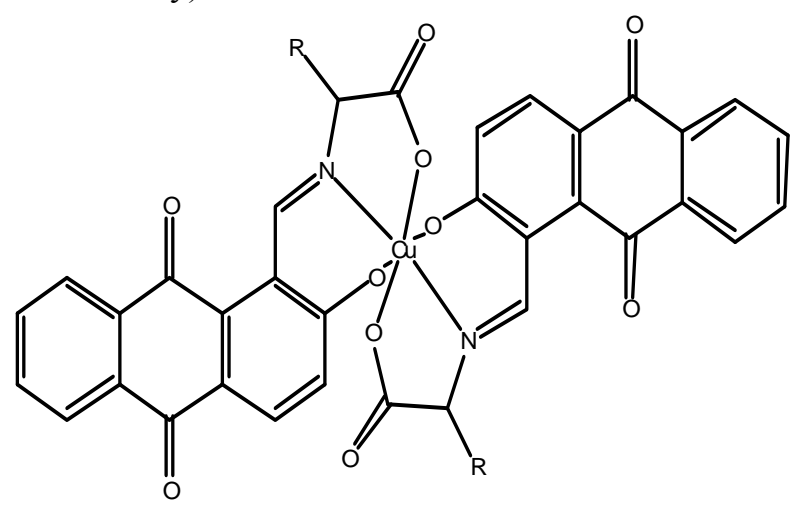

Scheme 1 Structures of $1\left(\mathrm{R}=\mathrm{CH}_{3}-\right), 2\left(\mathrm{R}=\left(\mathrm{CH}_{3}\right)_{2} \mathrm{CH}-\right), 3$ $\left(\mathrm{R}=\mathrm{C}_{6} \mathrm{H}_{5^{-}}\right)$.

Corresponding author: Takashiro Akitsu, professor, Ph.D. (Science), research fields: inorganic chemistry, coordination chemistry, crystallography.
Herein, we have attempted to overcome the spatial disadvantage of metal complex mediators [2-4] by designing ( 0 and) 1-3 (Scheme 1) by molecular design; (1) amino acid moiety and planar structure (molecular orientation in the hydrophobic pocket near the $\mathrm{T} 1 \mathrm{Cu}$ site) to enhance affinity to enzyme, (2) including redox-active moieties both organic ligand and metal ions.

\section{Experimental}

Chemicals of the highest commercial grade available (solvents from Kanto Chemical, organic compounds from Tokyo Chemical Industry and metal sources from Wako) were used as received without further purification. Electrodes of laccase and complexes were prepared and measured in our previous method [3].

2-hydroxy-anthraquinone-1-carbaldehyde was prepared according to the literature procedure [5]. Treatment with equimolar ( $R$ )-1-phenylethylamine in methanol at $313 \mathrm{~K}$ for $2 \mathrm{hr}$ to become yellow and stirring 0.5 equimolar copper(II) acetate for $1 \mathrm{hr}$ gave brown prismatic crystals of four-coordinated square planar 0 (Fig. 1). Yield 31.3\%. Anal. Found: C, 71.51; $\mathrm{H}, 4.22 ; \mathrm{N}, 3.66 \%$. Calcd. for $\mathrm{C}_{46} \mathrm{H}_{32} \mathrm{CuN}_{2} \mathrm{O}_{6}$ : C, 71.54; 
$\mathrm{H}, 4.18$; N, 3.63\%. IR 1,642 $\mathrm{cm}^{-1}(\mathrm{C}=\mathrm{N})$. UV-V is (acetate buffer) $220 \mathrm{~nm}\left(\pi-\pi^{*}\right)$, CD $210 \mathrm{~nm}(+)$.

Instead of 1-phenyleamine for $\mathbf{0}, \mathbf{1 - 3}$ were also prepared using the corresponding $L$-amino acids. Electrochemical (Fig. 2) and spectroscopic characterization with computational interpretation (Fig.

3) for only complexes 1-3 are depicted.

Elemental analyses $(\mathrm{C}, \mathrm{H}, \mathrm{N})$ were carried out with a Perkin-Elmer 2400II CHNS/O analyzer at Tokyo University of Science. Infrared spectra were recorded as $\mathrm{KBr}$ pellets on a JASCO FT-IR 4200 plus spectrophotometer in the range of $4,000-400 \mathrm{~cm}^{-1}$ at 298 K. Electronic spectra were measured on a JASCO V-570 UV/VIS/NIR spectrophotometer (equipped with an integrating sphere for diffuse reflectance spectra) in the range of $800-200 \mathrm{~nm}$ at $298 \mathrm{~K}$. CD (circular dichroism) spectra were measured as $\mathrm{KBr}$ pellets on a JASCO J-820 spectropolarimeter in the range of $800-200 \mathrm{~nm}$ at $298 \mathrm{~K}$. Electrochemical (cyclic voltammetry, CV) measurements were carried out on a BAS SEC2000-UV/VIS and ALS2323 system with $\mathrm{Ag} / \mathrm{AgCl}$ electrodes range of $-0.50-0.80$ V vs. $\mathrm{Ag} / \mathrm{Ag}^{+}$.

Crystals of $\mathbf{0}$ were glued on top of a glass fiber and coated with a thin layer of epoxy resin to measure the diffraction data. Intensity data were collected on a Bruker APEX2 CCD diffractometer with graphite monochromated Mo $\mathrm{K} \alpha$ radiation $(\lambda=0.71073 \AA)$. Data analysis was carried out with a SAINT program package. An empirical absorption correction was applied by a program SADABS [6]. The structures were solved by direct methods with a SHELXS-97 [7] and expanded by Fourier techniques and refined by full-matrix least-squares methods based on $\mathrm{F}^{2}$ using the program SHELXL-97 [7]. All non-hydrogen atoms were readily located and refined by anisotropic thermal parameters. All hydrogen atoms were located at geometrically calculated positions and refined using riding models.

Crystallographic data for 0 (CCDC 1455901): $\mathrm{C}_{46} \mathrm{H}_{32} \mathrm{CuN}_{2} \mathrm{O}_{3}, 0.31 \times 0.15 \times 0.10 \mathrm{~mm}^{3}, \mathrm{M}_{\mathrm{w}}=772.27$, monoclinic, $P 2_{1}$ (\#4), $a=12.6752(13), b=7.8327(8), c$



Fig. 1 Crystal structures of 0 . Selected bond distance $(\AA)$ and bond angles $\left({ }^{\circ}\right)$ : Cu1-O3 = 1.913(3), Cu1-O4 = 1.907(3), Cu1-N5 = 1.911(3), Cu1-N6 = 1.991(3), O3-Cu1-O4 = 177.33(16), N5-Cu1-N6 = 176.92(2). 

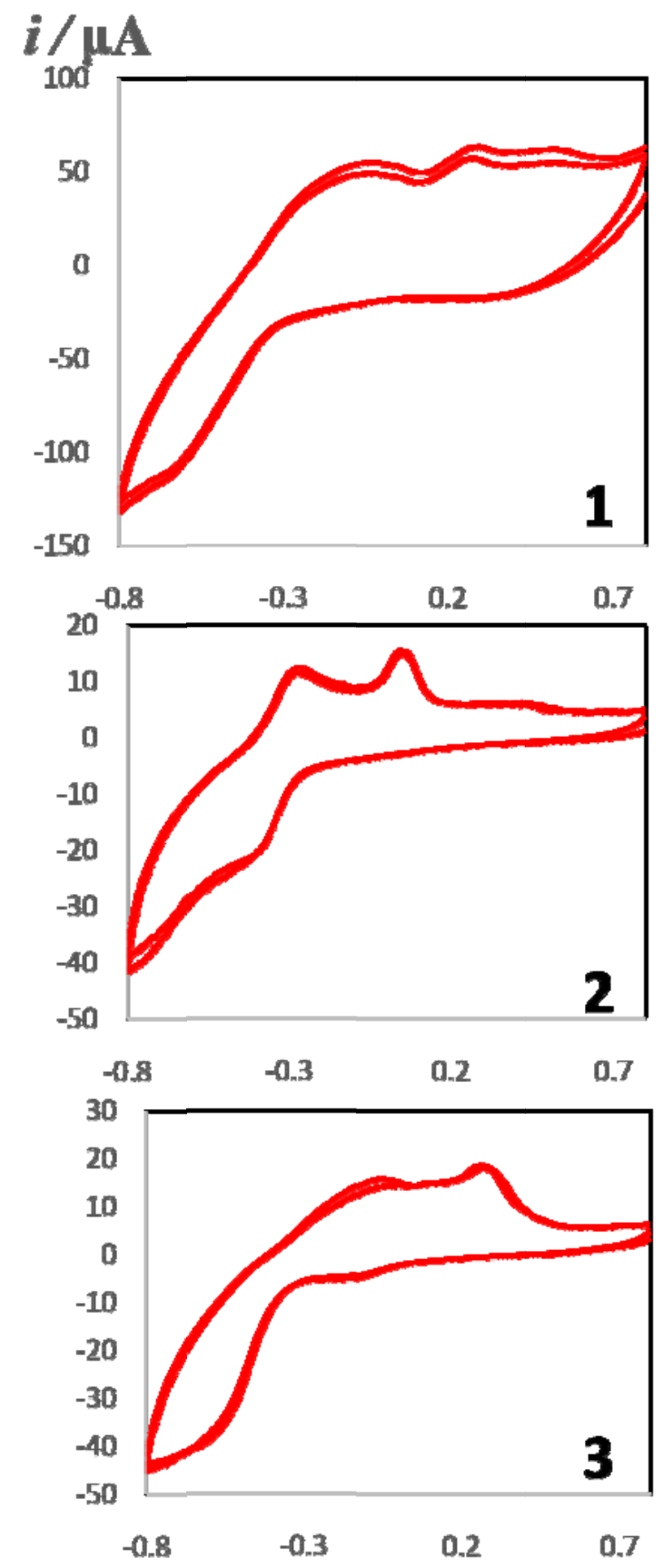

Potential(V vs. Ag/AgCl)

Fig. 2 CV (Ag/AgCl electrodes) for only 1-3.

$=17.9845(19) \AA, \beta=105.4861(11)^{\circ}, V=1720.7(3) \AA^{3}$, $Z=2, D_{\text {calc }}=1.491 \mathrm{mg} / \mathrm{m}^{3}, \mathrm{~F}(000)=798, \mathrm{R}_{1}=0.0384$, $\mathrm{wR}^{2}=0.1042$ (5762 reflections), $\mathrm{S}=0.735$, Flack parameter $=0.007$ (12).

All calculations were performed using the Gaussian 09W software Revision A.02 (Gaussian, Inc.) [8].
The gas phase geometry optimizations were carried out using TD-DFT with B3LYP functional. The vertical excitation energy was calculated with the Lanl2dz for $\mathrm{Cu}$ and with the $6-31+\mathrm{G}(\mathrm{d})$ basis set for $\mathrm{H}$, $\mathrm{C}, \mathrm{N}$ and $\mathrm{O}$ method based on the singlet ground state geometry. 
1.
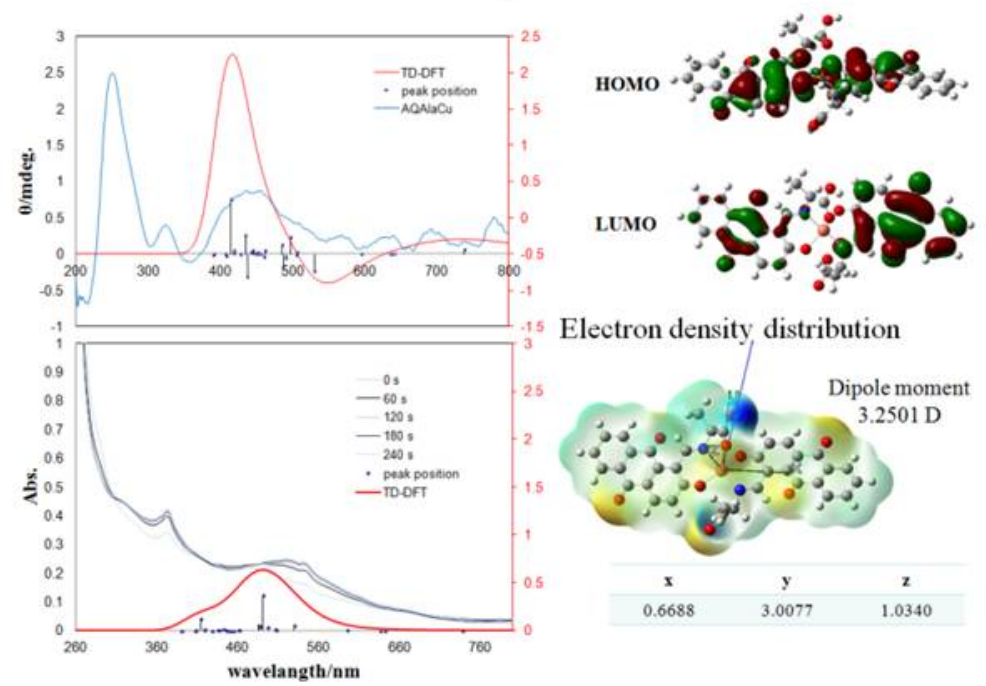

Electron density distribution



2.
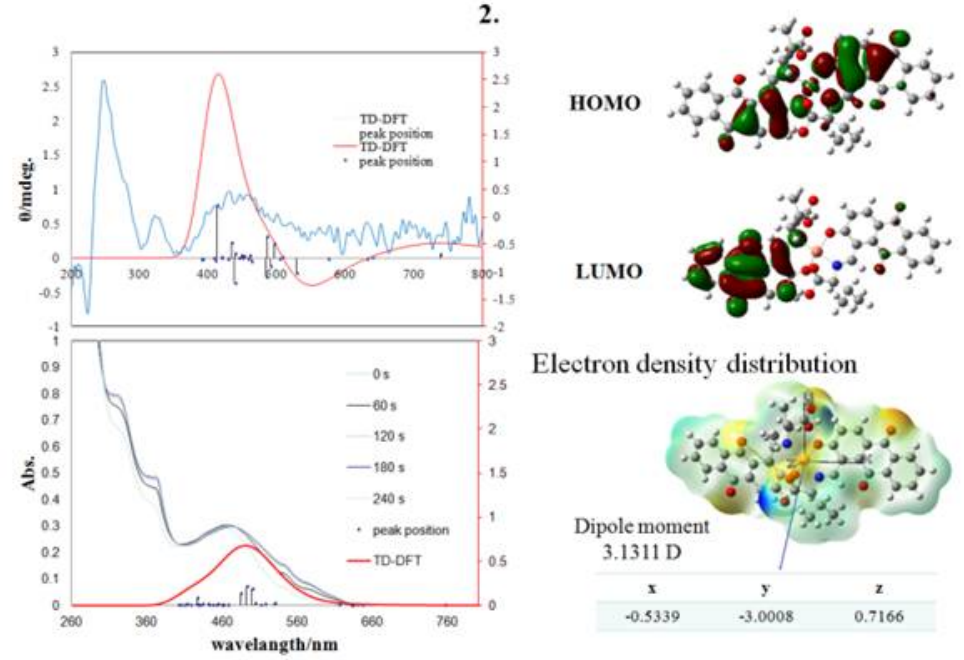

LUMO

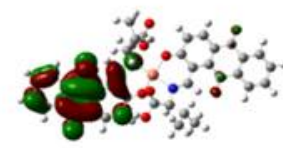

Electron density distribution

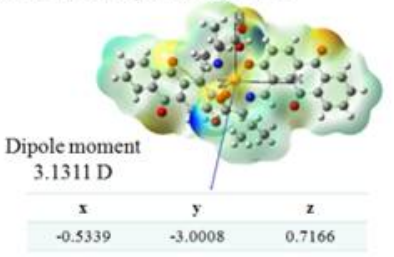

3.
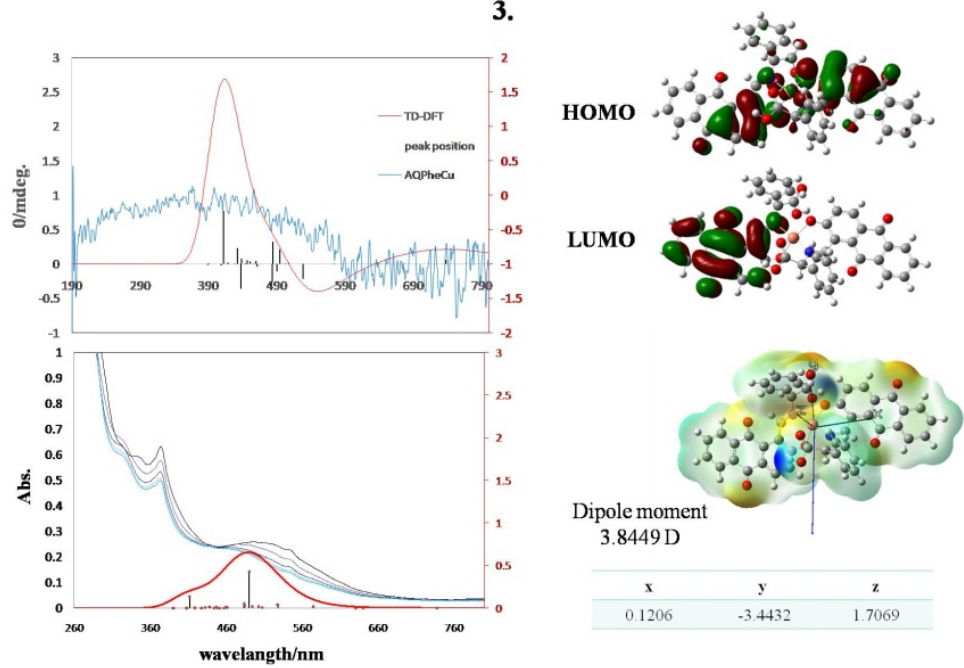

Fig. 3 Spectroelectrochemical data and theoretical calculation for 1-3 (TD-DFT, 6-31+G(d)). 

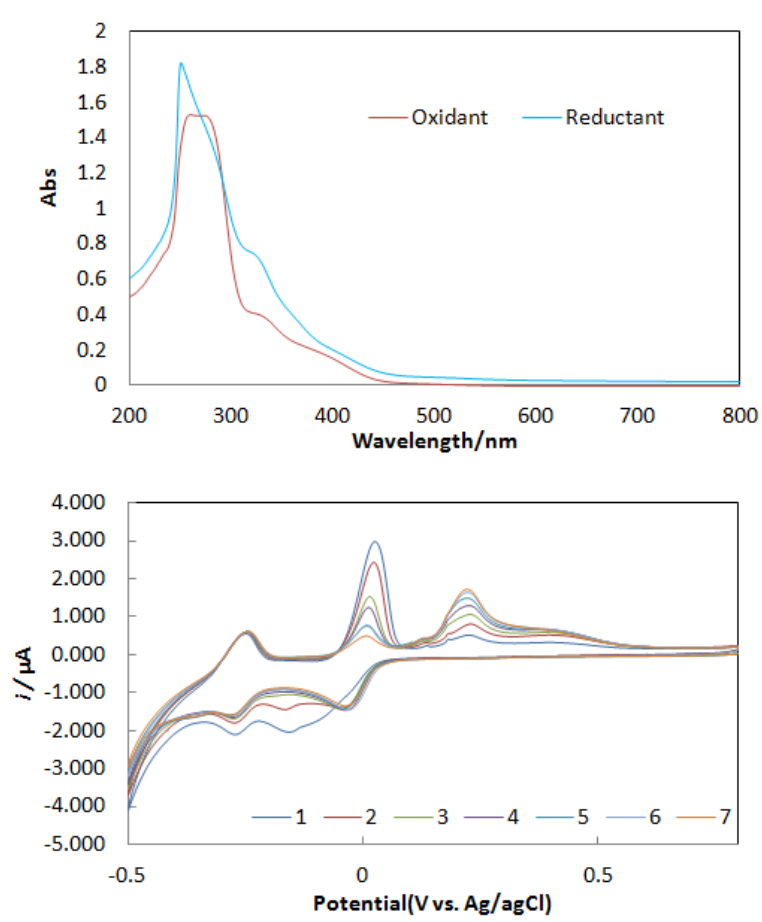

Fig. 4 Spectroelectrochemical data of (above) UV-vis (below) $\mathrm{CV}$ for oxygen-reducing laccase-0 hybrid system (0.1 $\mathrm{mg}$ of 1accase and $0.01 \mathrm{mg}$ of 0 in $\mathrm{pH} 4.0$ acetate buffer $10 \mathrm{~mL})$.

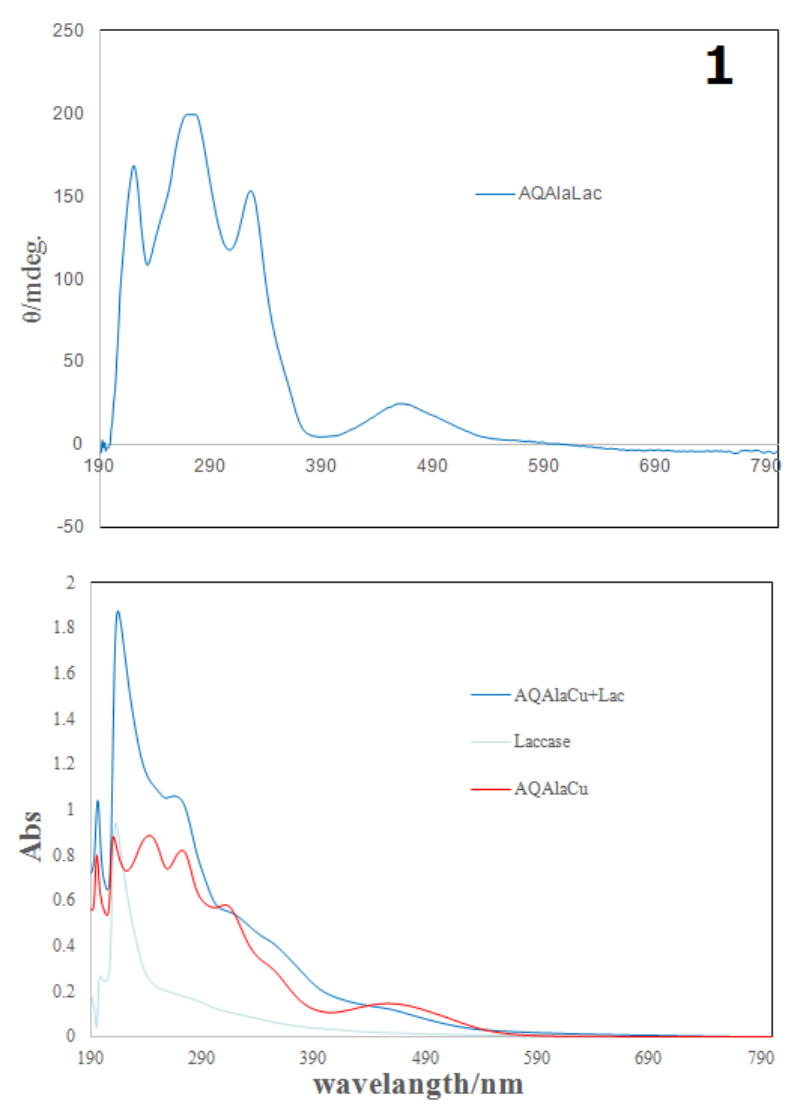

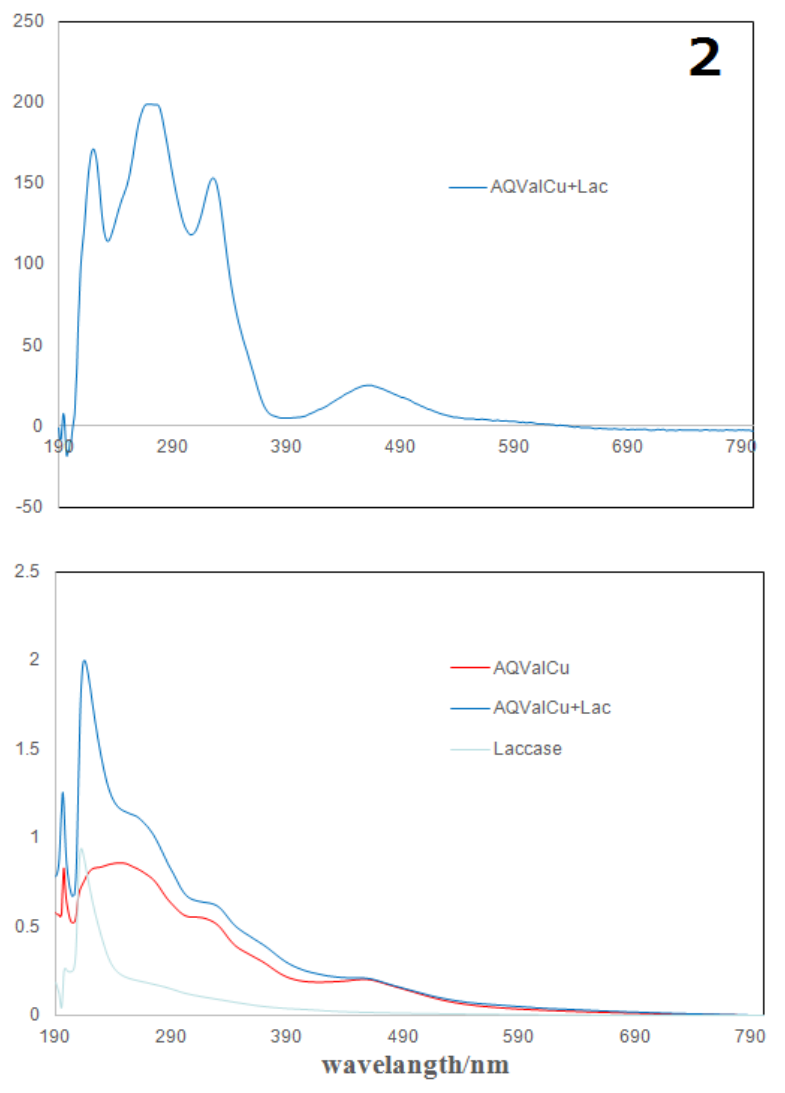
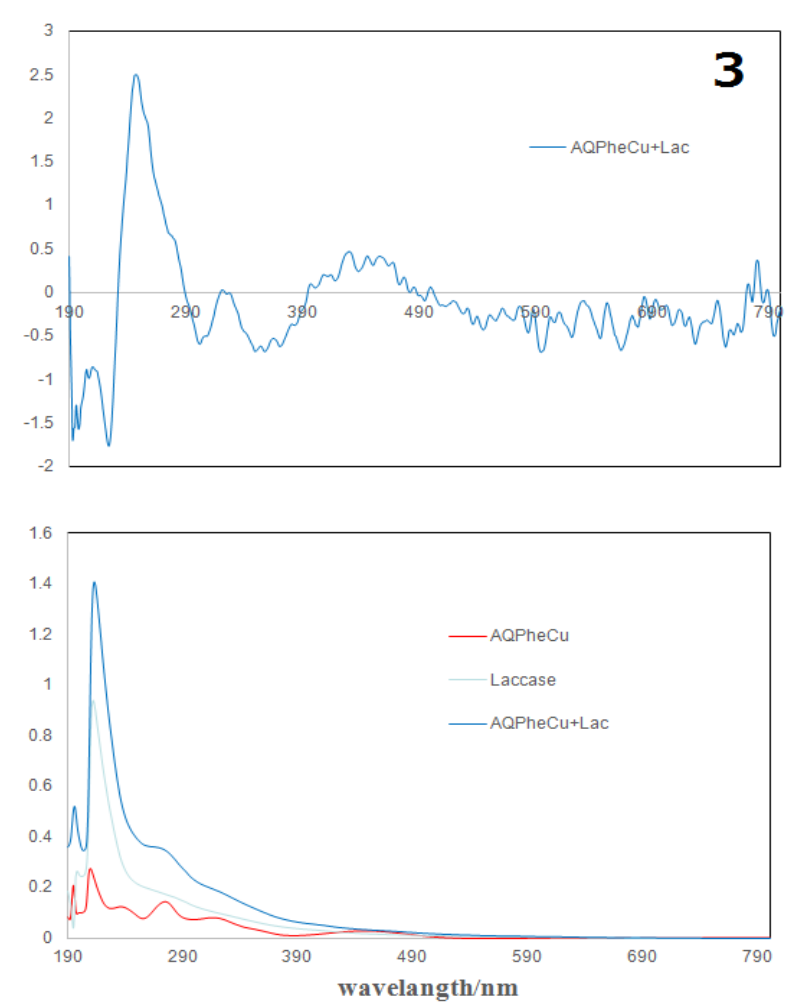

Fig. 5 CD (above) and UV-vis (below) spectral change of before (red) and after (blue) docking of 1-3 to laccase (green). 


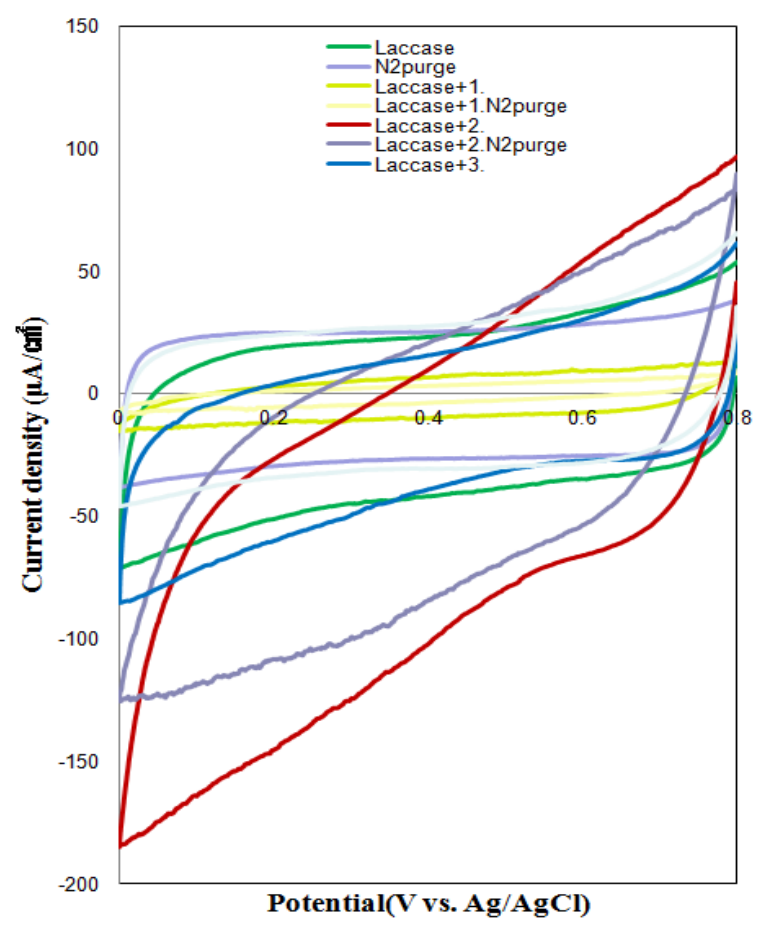

Fig. 6 Comparison of CVs of laccase-(1-3) hybrid systems in acetate buffer under air or $\mathrm{N}_{2}$ (pH 5.0. scan rate is $50 \mathrm{mV}$ $\left.\mathrm{s}^{-1}\right)$.

\section{Results and Discussion}

Fig. 4 showed a spectroelectrochemical proof of mediator function of $\mathbf{0}$ (reduction of oxygen is at about $540 \mathrm{mV}$ generally $[9,10])$, and that intermediate species exist in the new complex, in other words, quinone moiety of the ligand should be considered as the anion structure.

For laccase and (0 and) 1-3 hybrid systems (Fig. 5), monotonous increase of CD bands around 480 and 230 $\mathrm{nm}$ implied that the mediator preferentially binds to the hydrophobic pocket of laccase via appropriate intermolecular (electrostatic) interactions (as shown electron density distribution and dipole moments in the direction with the $\mathrm{x}, \mathrm{y}, \mathrm{z}$-coorinates in Fig. 3) and keeping secondary structure of laccase, respectively.

Fig. 6 and Table 1 also indicated the decreased current densities by nitrogen purging only were 31,7 , 58 , and $59 \mu \mathrm{A}$ for laccase only, laccase and 1-3, respectively.

Table 1 Decreasing current densities by $\mathrm{N}_{2}$ purge $(\mu \mathrm{A})$.

\begin{tabular}{llll}
\hline & $\mathrm{N}_{2}$ & Air & Differences \\
\hline laccase & -72 & -41 & -31 \\
laccase +1 & -15 & -8 & -7 \\
laccase +2 & -183 & -125 & -58 \\
laccase +3 & -83 & -44 & -39 \\
\hline
\end{tabular}



Scheme 2 A Cathode system using conventional metal complex mediators. 


\section{Conclusions}

By comparison with conventional (Scheme 2) or a control complex $\mathbf{0}$, improved mediators 1-3 have three advantages, which are as follows:

- Strong intermolecular interaction and suitable fitting between complexes (amino acid moiety) and laccase (surface) was expected.

- The current values of the oxygen reduction peak of laccase increased.

- The laccase/mediator biocathode could enhance the electrocatalytic current of $\mathrm{O}_{2}$ reduction.

\section{Acknowledgement}

The computations were performed using Research Center for Computational Science, Okazaki, Japan.

\section{Supplementary data}

CCDC 1455901 contains the supplementary crystallographic data for $1,4,5$, respectively. These data can be obtained free of charge via http://www.ccdc.cam.ac.uk/conts/retrieving.html, or from the Cambridge Crystallographic Data Centre, 12 Union Road, Cambridge CB2 1EZ, UK; fax: (+44) 1223-336-033; or e-mail: deposit@ccdc.cam.ac.uk.

\section{References}

[1] Goff, L., Holzinger, M., and Cosnier, S. 2015. "Recent Progress in Oxygen-Reducing Laccase Biocathodes for Enzymatic Biofuel Cells." Cell. Mol. Life. Sci. 72: 941

[2] Kurosawa, Y., Tsuda, E., Takase, M., Yoshida, N., Takeuchi, Y., Mitsumoto, Y., and Akitsu, T. 2015. Threonine: Food Sources, Functions and Health Benefits. NY, USA: Nova Science Publishers, Inc., 73.

[3] Ogikubo, Y., Sano, A., Nagano, K., and Akitsu, T.
Laccase: Applications, Investigations and Insights. NY, USA: Nova Science Publishers, Inc. (in Press).

[4] Ogikubo, Y., and Akitsu, T. 2016. "Enhancing Medical or Biological Functions of Laccase by Cyanide-Bridged $\mathrm{Cu}(\mathrm{II})-\mathrm{Fe}(\mathrm{III})$ Bimetallic Complexes Madiators." Drug Designing: Open Access 5: 130.

[5] Fkyerat, G., Dubin, M., and Tabacchi, R. 1991. "The Synthesis of Natural Acetylenic Compounds from Stereum Hirsutum." Helvetica Chimica Acta 82: 1418.

[6] Sheldrick, G. M. 2008. "Short History of SHELX." Acta Cryst. A64: 112.

[7] Bruker. 2001. SADABS. Madison, Wisconsin, USA: Bruker AXS Inc.

[8] Frisch, M. J., Trucks, G. W., Schlegel, H. B., Scuseria, G. E., Robb, M. A., Cheeseman, J. R., Scalmani, G., Barone, V., Mennucci, B., Petersson, G. A., Nakatsuji, H., Caricato, M., Li, X., Hratchian, H. P., Izmaylov, A. F., Bloino, J., Zheng, G., Sonnenberg, J. L., Hada, M., Ehara, M., Toyota, K., Fukuda, R., Hasegawa, J., Ishida, M., Nakajima, T., Honda, Y., Kitao, O., Nakai, H., Vreven, T., Montgomery Jr., J. A., Peralta, J. E., Ogliaro, F., Bearpark, M., Heyd, J. J., Brothers, E., Kudin, K. N., Staroverov, V. N., Keith, T., Kobayashi, R., Normand, J., Raghavachari, K., Rendell, A., Burant, J. C., Iyengar, S. S., Tomasi, J., Cossi, M., Rega, N., Millam, J. M., Klene, M., Knox, J. E., Cross, J. B., Bakken, V., Adamo, C., Jaramillo, J., Gomperts, R., Stratmann, R. E., Yazyev, O., Austin, A. J., Cammi, R., Pomelli, C., Ochterski, J. W., Martin, R. L., Morokuma, K., Zakrzewski, V. G., Voth, G. A., Salvador, J. J., Dannenberg, S., Dapprich, A. D., Daniels, O., Farkas, P., Foresman, J. B., Ortiz, J. V., Cioslowski, J., and Fox, D. J. 2009. Gaussian 09, Revision D.01. Wallingford CT: Gaussian, Inc.

[9] Cardoso, F. P., Neto, S. A., Fenga, P. G., Ciancaglini, P., and De Andrade, A. R. 2013. "Electrochemical Characterization of Methanol/O2 Biofuel Cell: Use of Laccase Biocathode Immobilized with Polypyrrole Film and PAMAM Dendrimers." Electrochim. Acta 90: 90.

[10] Parimi, N. S., Umasankar, Y., Atanassov, P., and Ramasamy, R. P. 2011. "Kinetic and Mechanistic Parameters of Laccase Catalyzed Direct Electrochemical Oxygen Reduction Reaction.” ACS Catal. 2: 38. 